\title{
Serum selenium levels are associated with age-related cataract
}

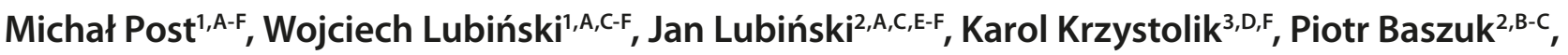 \\ Magdalena Muszyńska ${ }^{2, B-C}$, Wojciech Marciniak ${ }^{2, B-C}$ \\ 1 2nd Department of Ophthalmology, Pomeranian Medical University, Szczecin, Poland \\ 2 Department of Genetics and Pathomorphology, Pomeranian Medical University, Szczecin, Poland \\ ${ }^{3}$ 1st Department of Ophthalmology, Pomeranian Medical University, Szczecin, Poland \\ A - Research concept and design, B - Collection and/or assembly of data, C - Data analysis and interpretation, \\ $D$ - Writing the article, $E$ - Critical revision of the article, $F$ - Final approval of article
}

Post M, Lubiński W, Lubiński J, Krzystolik K, Baszuk P, Muszyńska M, Marciniak W. Serum selenium levels are associated with age-related cataract. Ann Agric Environ Med. 2018; 25(3): 443-448. doi: 10.26444/aaem/90886

\begin{abstract}
Objective. The aim of the study is to analyse correlations between age-related cataract (ARC), serum selenium levels and glutathione peroxidase gene 1 and 4 (GPX-1 and GPX-4).

Materials and method. A total sample of 275 participants were enrolled into the study: group A, 94 subjects elligible for ARC surgery, and group B, 181 volunteers without ocular symptoms, gender-, age-, and smoking- status and volume-matched at 1:2 with subjects in group A. All participants $(n=275)$ were divided according to the Lens Opacities Classification System III (LOCS III) into: 1) study group (subjects with clinically significant cataract; $\mathrm{N} \geq 3$ or $\mathrm{C} \geq 3$ or $\mathrm{P} \geq 2$ ), 2) control group (controls with clinically non-significant cataract; $\mathrm{N}<3$ and $\mathrm{C}<3$ and $\mathrm{P}<2$ ). The single nucleotide polymorphisms of GPX-1 and GPX-4 were assessed using Real Time PCR. Serum selenium levels were assayed using Inductively Coupled Plasma Mass Spectrometry. Results. Low selenium levels significantly predicted any age-related cataract (OR 7.969; $\mathrm{p}<.01)$, nuclear cataract (OR 12.823; $\mathrm{p}<.01$ ) and cortical cataract (OR 3.31; $\mathrm{p}<.01$ ). There was no significant effect of gender, age, SNP GPX-1 and SNP GPX-4 on the prevalence of age-related nuclear, cortical and posterior sub-capsular cataract. Serum selenium levels of $75-85 \mu \mathrm{g} / \mathrm{L}$ were associated with the lowest prevalence of ARC.

Conclusions. Due to a confirmed association between serum selenium levels and age-related cataract, low serum selenium levels may constitute a potential risk factor of age-related cataract.
\end{abstract}

Key words

selenium, age-related cataract, single nucleotide polymorphism, LOCS III, glutathione peroxidase, SNP

\section{INTRODUCTION}

According to the World Health Organisation (WHO, 2016), age-related cataract (ARC) is a cause of moderate or severe vision impairment in 50 million people worldwide [1]. Currently, the only effective treatment involves surgical cataract extraction with intraocular lens implantation. In the USA, cataract surgery is the most common type of surgery with 3 million procedures performed each year [2], and the annual cost of ARC treatment is approximately USD 3.5 billion [2]. ARC surgery rates in the US are high, over 8,000 procedures/ 1 million inhabitants, although in the developing countries it can be only 50 procedures/ 1 million inhabitants [3]. According to the WHOs estimates, in order to fully meet the growing need for treatment, the number of cataract surgery procedures worldwide would have to triple in 2000-2020 [3]. Considering population growth and ageing in developed countries and high costs of surgery, widely-available and effective cataract treatment still seems an unmet need. Therefore, alternative, non-surgical methods are being sought to inhibit lens opacity. The etiology of ARC has been studied extensively within the last 20 years, with particular focus on slowing the progression/delaying the

Address for correspondence:Wojciech Lubiński, 2nd Department of Ophthalmology Pomeranian Medical University in Szczecin, Poland

e-mail: lubinski@pro.onet.pl

Received: 06.04.2018; accepted: 09.05.2018; first published: 24.05.2018 onset of ARC [4-7]. However, the attempts so far have been unsuccessful.

Lens ageing and ARC are associated with a number of biochemical changes to the crystalline lens. These are primarily affected by oxidative stress, due to the presence of reactive oxygen species (ROS) [8,9]. Glutathione/ glutathione peroxidase 1 and 4 (GSH/GPX1/GPX-4) is the key enzyme system involved in protecting the lens against ROS-induced damage $[10,11]$. Glutathione peroxidase 1 and 4 are known as selenoproteins which, owing to their selenocysteine content, their enzymatic effect is 1,000 -fold stronger than their cysteine homologues [12]. A number of studies in humans and animals have confirmed a decreased activity of GPX and glutathione in a opacified lens [13-17]. Furthermore, an increased level of hydrogen peroxide $\mathrm{H}_{2} \mathrm{O}_{2}$ (which is reduced by GPX) was shown in the aqueous humour of patients with cataracts [18-20]. The role of GPX activity in cataract formation (especially nuclear cataract) has been well established $[13,18,21,22]$. Lens opacity, especially within the nucleus, developed significantly faster in GPX knockout mice $[21,22]$.

The GPX activity is selenium-dependent. The suggested serum Se levels in humans, optimum for GPX and other selenoprotein function range between $78.9 \mu \mathrm{g} / \mathrm{L}$ and $94.7 \mu \mathrm{g} / \mathrm{L}$ (1.00-1.20 mmol/L) [23-25]. Knowledge of serum Se levels in patients with ARC may provide essential data relative to lens metabolism and human health. There are many reports suggesting that suboptimum Se levels may increase the risk of 
cancers (i.e. laryngeal), as well as cardiovascular, pulmonary, and inflammatory diseases [10, 22, 23, 28]. Moreover, single reports suggest that suboptimum Se levels may adversely affect lens metabolism, increasing its opacity [21]. This appears to be particularly relevant in the Polish population, with the low mean serum Se level of $70 \mu \mathrm{g} / \mathrm{l}$, while in North America the average reported Se concentration ranges from 122.4-151.8 $\mu \mathrm{g} / 1$ [26-28]. Serum selenium levels may differ among populations, depending on a number of factors, including but not limited to concentration of selenium in food, water (groundwater in Poland $\mathrm{Se}=0.05 \mu \mathrm{g} / \mathrm{L}$ ), soil [2628]. More than $77 \%$ of the area of Poland is characterized by a decreased level of Se in soil, the lowest in the eastern regions $-0.06-0.4 \mathrm{mg} / \mathrm{kg}$, the highest in northwestern regions $-2.3-4.2 \mathrm{mg} / \mathrm{kg}$. At the same time, Se level in soil in the USA is $6-15 \mathrm{mg} / \mathrm{kg}$. The concentration of selenium is also dependent on the industrialization of the region (USA - $30 \mathrm{ng} / \mathrm{m}^{3}$, South Pole $-0.004-0.008 \mathrm{ng} / \mathrm{m}^{3}$ ). These data confirm the thesis that the selenium concentration is strongly dependent on both environmental factors and pollution.

Single nucleotide polymorphism (SNP) is a variation in the DNA sequence, involving a single nucleotide (A,T,C or $\mathrm{G})$ change between the corresponding chromosomes of a given individual. In GPX-1 and GPX-4 genes, polymorphisms involving thymine $(\mathrm{T})$ and cytosine $(\mathrm{C})$ changes are of key functional importance. These may present as CC/CT/ TT genotypes [30-32]. However, the SNP GPX have not been assessed in ophthalmology. The current study is the first analysis of SNP GPX-1 (rs1050450) and SNP GPX-4 (rs713041) in patients with ARC. Detailed characteristics of genes and single nucleotide polymorphisms (SNP) of GPX 1 and GPX 4 are shown in Table 1.

Research supports the crucial role of GPX-1 and GPX-4 in lens metabolism and pathophysiology of ARC. There are single reports suggesting the role of selenium in regulating the enzymes in question. A detailed analysis of the above may significantly contribute to our understanding of cataract prevention. This is particularly important in the context of increasing ARC prevalence in the general population, and the related treatment needs and costs.

Table 1. Characteristics of glutathione peroxidase genes 1 and 4

\begin{tabular}{llcccc}
\hline $\begin{array}{l}\text { Chromosome/ } \\
\text { gene }\end{array}$ & Function & SNA & Position & SNP locus & Allele \\
\hline 3p21/GPX-1 & $\begin{array}{l}\text { GPX-1 enzyme } \\
\text { detoxifies } \\
\mathrm{H}_{2} \mathrm{O}_{2} \text { and lipid } \\
\text { hydroperoxides }\end{array}$ & rs1050450 & 49357401 & $\begin{array}{c}\text { Pro198Leu } \\
\text { (exon } \\
198)\end{array}$ & $\mathrm{C} / \mathrm{T}$ \\
\hline & $\begin{array}{l}\text { GPX-4 enzyme, } \\
\text { reduces } \mathrm{H}_{2} \mathrm{O}_{2} \text { and } \\
\text { phospholipid } \\
\text { hydroperoxides }\end{array}$ & rs713041 & 1106616 & $3-$ UTR & $\mathrm{C} / \mathrm{T}$ \\
\hline
\end{tabular}

GPX - 1 glutathione peroxidase $1 ; \mathrm{GPX}-4$ - glutathione peroxidase $4 ; \mathrm{H}_{2} \mathrm{O}_{2}$ hydrogen peroxide $\mathrm{SNP}$ - single nucleotide polymorphism; Pro - praline; Leu - leucine; $\mathrm{C}^{2}$ - cytosine; $\mathrm{T}$ - thymine; 3-UTR - untranslated region.

\section{MATERIALS AND METHOD}

Participants. A total sample of 275 individuals (103 men, 172 women) were enrolled, including:

A) 94 patients eligible for age-related cataract surgery at the Ophthalmology Outpatient Clinic who were intended as the core of the study group. The mean age in this subgroup was 72.4 years \pm 7.25 (range: $56-89$ years). B) 181 volunteers without ocular symptoms, matched at 1:2 to the patients from group $\mathrm{A}$, the core of the control group. The controls were matched to patients based on: year of birth ( \pm 3 years), gender, number of packet-years $\pm 20 \%$ (packet-years defined as the number of cigarette packets smoked daily, multiplied by the number of years an individual has been a smoker). Group $B$ was recruited from the Genetic Oncology Outpatient Clinic. Pedigree and clinical characteristics of hereditary malignancies were equally present in groups A and B. Highrisk mutation carriers were excluded. The mean age in this subgroup was 70.9 years \pm 7.36 (range: $53-88$ years).

In order to control for the confounding variables, strict inclusion/exclusion criteria were applied. Exclusion criteria included taking prescription medications, the presence of diseases known to effect the lens, as well as eye diseases other than age-related cataract. Thus, an individual with diabetes and fasting hyperglycaemia was excluded in order to minimise the role of glycation products and sorbitol in cataract development in the study sample. Furthermore, individuals taking micro-/macroelement and/ or vitamin-based supplements were excluded, along with those on a reduction or therapeutic diet. Medical history ascertained such factors as excessive exposure to UV or IR radiation in, e.g. the high-risk professions of a steel worker or a welder.

All participants $(n=275)$ were classified into the study group according to the Lens Opacities Classification Scale III (LOCS III) - subjects with clinically significant cataract, or the control group - controls with clinically non-significant cataract (Tab. 2). The division between clinically significant and non-significant cataract was determined as in previous research [33-35], despite which there is still no formal cataract classification into those clinically significant and non-significant.

The rs1050450 genotype of GPX-1 and rs713041 genotype of GPX- 4 were assessed in 275 enrolled participants. The CT and TT genotypes were jointly referred to as non-CC, on the grounds of similarities in their function. The CC GPX-1 genotype constituted $46.18 \%$ of all GPX-1 polymorphisms and the non-CC genotype was shown in 148 participants (53.82\%). The CC GPX-4 genotype (rs713041) constituted $35.64 \%$ of all GPX- 4 polymorphisms, and the non-CC genotype was shown in $64.36 \%$ of all participants.

All participants gave their informed consent to participate in the study. The study protocol, designed in accordance with the Declaration of Helsinki, was approved by the Internal Review Board at the Pomeranian Medical University in Szczecin.

Selenium level assay in biological samples. Venous blood samples of all patients were obtained in the morning (fasting) and frozen at $-80 \mathrm{C}$ within $2 \mathrm{hrs}$ following collection. Selenium levels were assayed in serum, which is used the most often for selenium level measurements in research [26, 27]. Selenium in serum determination was carried out using the Inductively Coupled Plasma-Mass Spectrometer (ICPMS). Serum specimens were initially centrifuged at 3,000 $\mathrm{G}$ for 10 minutes. Next, the supernatant volume was diluted 100 -fold with $0.65 \%$ nitric acid solution SUPRAPUR (Merck, Germany). The processed sample was then used for selenium 
Table 2. Study group classification by cataract grading (LOCS III)

\begin{tabular}{|c|c|c|c|c|c|c|c|c|}
\hline \multirow{2}{*}{ Opacity } & \multicolumn{4}{|c|}{$\begin{array}{l}\text { Controls (with clinically non- } \\
\text { significant cataract as per LOCS } \\
\text { III) }\end{array}$} & \multicolumn{4}{|c|}{$\begin{array}{l}\text { Subjects (with clinically } \\
\text { significant cataract as per } \\
\text { LOCS III) }\end{array}$} \\
\hline & $\begin{array}{c}\text { LOCS } \\
\text { III }\end{array}$ & $\begin{array}{c}\text { Group } \\
\text { A }\end{array}$ & $\begin{array}{c}\text { Group } \\
\text { B }\end{array}$ & Total & $\begin{array}{c}\text { LOCS } \\
\text { III }\end{array}$ & $\begin{array}{c}\text { Group } \\
\text { A }\end{array}$ & $\begin{array}{c}\text { Group } \\
\text { B }\end{array}$ & Total \\
\hline nuclear ${ }^{*}$ & $\mathrm{~N}<3$ & $n=7$ & $n=168$ & $n=175$ & $\mathrm{~N} \geq 3$ & $n=87$ & $n=13$ & $n=100$ \\
\hline cortical & $C<3$ & $n=16$ & $n=136$ & $n=152$ & $C \geq 3$ & $n=78$ & $n=45$ & $n=123$ \\
\hline $\begin{array}{l}\text { posterior } \\
\text { subcapsular }\end{array}$ & $\mathrm{P}<2$ & $n=42$ & $n=150$ & $n=192$ & $P \geq 2$ & $\mathrm{n}=52$ & $n=31$ & $n=83$ \\
\hline $\begin{array}{l}\text { Any age- } \\
\text { related } \\
\text { cataract }\end{array}$ & $\begin{array}{l}\mathrm{N}<3 \\
\text { and } \\
\mathrm{C}<3 \\
\text { and } \\
\mathrm{P}<2\end{array}$ & $n=0$ & $n=106$ & $n=106$ & $\begin{array}{l}\mathrm{N} \geq 3 \text { or } \\
\mathrm{C} \geq 3 \text { or } \\
\mathrm{P} \geq 2\end{array}$ & $\mathrm{n}=94$ & $n=75$ & $n=169$ \\
\hline
\end{tabular}

*N determined as a mean of NO (nuclear opalescence) and NC (nuclear colour)

determination using ICP-MS (Elan DRC-e, PerkinElmer, USA). The quantitative assay required a calibration curve. Therefore, a multi-element calibration standard was created using dilution (Multi-Element Calibration Standard 3; PerkinElmer, USA), with the endpoint concentrations of calibration standards of $0.1 \mu \mathrm{g} / \mathrm{L}, 1 \mu \mathrm{g} / \mathrm{L}, 5 \mu \mathrm{g} / \mathrm{L}$ and $10 \mu \mathrm{g} / \mathrm{L}$, respectively. Serum control with the verified selenium content (ClinChek ${ }^{\oplus}$ Serum Control, RECIPE, Germany) was used as the reference sample. The ICPMS method used in the sample-processing laboratory was validated by international reference centres.

Selenoprotein gene variant determination. The realtime PCR (LightCycler 480 II, Roche Diagnostics GmbH, Germany) was used for gene quantification. Functional DNA fragments with high polymorphism were selected for analyses. The following genes were analysed: GPX-1 (RS1050450) and GPX-4 (RS713041).

Statistical analysis. A sample of 275 participants was divided into quartiles $(n=68,69)$ according to their serum selenium levels, with the 1st quartile presenting with the lowest (31.64-67.73 $\mu \mathrm{g} / \mathrm{L})$ and 4 th quartile - with the highest (81.29$163.54 \mu \mathrm{g} / \mathrm{L})$ levels. The 3rd quartile $(75.18-81.28 \mu \mathrm{g} / \mathrm{L})$ was a reference group, as their lens opacity as per LOCS III was the lowest; therefore, they were the most representative of the general population. Cataract was graded as per LOCS III (Tab. 2).

Multiple logistic regression was used in order to identify factors significantly predicting increased prevalence of ARC in the study sample. This included all ARC subtypes. The analysed variables included: age, gender, serum selenium level, as well as the polymorphism (CC vs. non-CC) of GPX-1 and GPX-4. The confidence interval ranged between 2.5\%$97.5 \%$, with $\mathrm{p}<.05$ considered statistically significant. Each type of ARC was assessed as an independent variable, just as performed in some other studies in this field $[34,35]$.

\section{RESULTS}

All participants had an intraocular pressure (IOP) of 8-21 $\mathrm{mmHg}$ and normal fundus morphology. The best distance corrected visual acuity (BDCVA) fell within the range of.02 -.1 (logMAR). The results of multiple logistic regression are shown in Tables 3-6. The $3^{\text {rd }}$ quartile of Se levels was not included as a reference range. Low serum selenium levels (within the 1st quartile range) significantly predicted any cataract (Tab. 3), and - in particular - nuclear (Tab. 4) and cortical (Tab. 5) cataract in the study sample. The incidence of any age-related cataract was 8-fold higher than in the general population, with serum selenium levels within the 1st quartile (range: $31.64-67.73 \mu \mathrm{g} / \mathrm{L}$ ): OR 7.969, CI 95\% 3.391-20.672; $\mathrm{p}<.01$ (Tab. 3). The lowest incidence of ARC was observed in the subgroup of participants with serum Se levels ranging between $75 \mu \mathrm{g} / \mathrm{L}-85 \mu \mathrm{g} / \mathrm{L}$, which broadly corresponds with the 3 rd quartile Se levels. There was no significant association between gender or age and age-related cataract prevalence (Tab. 3). There was no effect of SNP of GPX-1 or GPX-4 on the incidence of ARC. The statistics relative to the CC-genotype are shown in Tables 3-6. As none of these values was statistically significant, it can be assumed that the CC-genotype does not affect the incidence of ARC.

Table 3. Factors associated with increased incidence of any age-related cataract - multiple logistic regression

\begin{tabular}{|c|c|c|c|c|}
\hline Assessed factor & OR & $2.5 \%$ & $97.5 \%$ & $\mathrm{p}$ \\
\hline $\begin{array}{l}\text { Se 1st quartile (Se levels range of } \\
31.64-67.73 \mu \mathrm{g} / \mathrm{L} \text { ) }\end{array}$ & 7.969 & 3.391 & 20.672 & $<.01$ \\
\hline $\begin{array}{l}\text { Se } 2 \text { nd quartile (Se levels range of } \\
67.74-75.17 \mu \mathrm{g} / \mathrm{L} \text { ) }\end{array}$ & 1.465 & 0.742 & 2.918 & .273 \\
\hline $\begin{array}{l}\text { Se } 4 \text { th quartile (Se levels range of } \\
81.29-163.54 \mu \mathrm{g} / \mathrm{L} \text { ) }\end{array}$ & 1.117 & 0.567 & 2.211 & .749 \\
\hline age & 1.019 & 0.981 & 1.059 & .325 \\
\hline Gender (male) & 1.188 & 0.686 & 2.076 & .541 \\
\hline CC genotype of GPX-1 & 1.499 & 0.888 & 2.552 & .132 \\
\hline CC genotype of GPX-4 & 0.785 & 0.456 & 1.349 & .38 \\
\hline
\end{tabular}

The results of multiple logistic regression for nuclear and cortical cataract are shown in Tables 4 and 5, respectively. Subjects with the lowest Se levels (1st quartile) had a 12-fold higher occurrence of nuclear opacity: OR 12.823; CI 95\% $5.672-30.972 ; \mathrm{p}<.01$. The prevalence of cortical cataract was lower, yet significant: OR 3.31; CI 95\% 1.635-6.866; p<.01. There was no significant effect of SNP GPX-1 and SNP GPX-4, gender or age. The results of multiple logistic regression for posterior sub-capsular cataract are shown in Table 6. There was no effect of selenium levels, gender, age, SNP GPX-1 or SNP GPX-4 on the incidence of this type of cataract.

Table 4. Factors associated with increased incidence of nuclear cataract - multiple logistic regression

\begin{tabular}{lcccc}
\hline Assessed factor & OR & $2.5 \%$ & $97.5 \%$ & $\mathrm{p}$ \\
\hline $\begin{array}{l}\text { Se level in the 1st quartile (range } \\
\text { of } 31.64-67.73 \mu \mathrm{g} / \mathrm{L})\end{array}$ & 12.823 & 5.672 & 30.972 & $<.01$ \\
\hline $\begin{array}{l}\text { Se level in the } 2 \mathrm{nd} \text { quartile (range } \\
\text { of } 67.74-75.17 \mu \mathrm{g} / \mathrm{L})\end{array}$ & 1.709 & 0.753 & 3.979 & .204 \\
\hline $\begin{array}{l}\text { Se level in the 4th quartile (range } \\
\text { of } 81.29-163.54 \mu \mathrm{g} / \mathrm{L})\end{array}$ & 1.745 & 0.766 & 4.082 & .19 \\
\hline age & 1.044 & 1.002 & 1.089 & .043 \\
\hline sex (male) & 1.605 & 0.874 & 2.979 & .129 \\
\hline CC genotype of GPX-1 & 1.445 & 0.819 & 2.571 & .206 \\
\hline CC genotype of GPX-4 & 0.646 & 0.351 & 1.172 & .155 \\
\hline
\end{tabular}


Table 5. Factors associated with increased incidence of cortical cataract - multiple logistic regression

\begin{tabular}{lcccc}
\hline Assessed factor & OR & $2.5 \%$ & $97.5 \%$ & $\mathrm{p}$ \\
\hline $\begin{array}{l}\text { Se levels in the 1st quartile (range of } \\
\text { 31.64-67.73 } \mu \mathrm{g} / \mathrm{L})\end{array}$ & 3.31 & 1.635 & 6.866 & $<.01$ \\
\hline $\begin{array}{l}\text { Se levels in the 2nd quartile (range of } \\
67.74-75.17 \mu \mathrm{g} / \mathrm{L})\end{array}$ & 1.317 & 0.66 & 2.642 & .435 \\
\hline $\begin{array}{l}\text { Se levels in the 4th quartile (range of } \\
81.29-163.54 \mu \mathrm{g} / \mathrm{L})\end{array}$ & 1.036 & 0.513 & 2.093 & .921 \\
\hline age & 1 & 0.965 & 1.037 & .992 \\
\hline gender (male) & 1.365 & 0.809 & 2.315 & .245 \\
\hline CC genotype of GPX-1 & 1.115 & 0.679 & 1.834 & .667 \\
\hline CC genotype of GPX-4 & 0.973 & 0.579 & 1.63 & .916 \\
\hline
\end{tabular}

Table 6. Factors associated with increased incidence of posterior subcapsular cataract - multiple logistic regression

\begin{tabular}{lcccc}
\hline Assessed factor & OR & $\begin{array}{c}2.5 \\
\%\end{array}$ & $\begin{array}{c}97.5 \\
\%\end{array}$ & P \\
\hline Se levels in the 1st quartile (range of $31.64-67.73 \mu \mathrm{g} / \mathrm{L})$ & 2.02 & 0.96 & 4.36 & .07 \\
\hline Se levels in the 2nd quartile (range of $67.74-75.17 \mu \mathrm{g} / \mathrm{L})$ & 1.72 & 0.82 & 3.68 & .15 \\
\hline Se levels in the 4th quartile (range of $81.29-163.54 \mu \mathrm{g} / \mathrm{L})$ & 0.91 & 0.40 & 2.02 & .81 \\
\hline age & 1.01 & 0.97 & 1.05 & .51 \\
\hline gender (male) & 1.48 & 0.85 & 2.60 & .17 \\
\hline CC genotype of GPX-1 & 1.16 & 0.68 & 1.98 & .58 \\
\hline CC genotype of GPX-4 & 0.76 & 0.43 & 1.32 & .33 \\
\hline
\end{tabular}

\section{DISCUSSION}

Selenium is a micronutrient with a complex metabolism with multi-factorial regulation of its activity. Its concentration in the body depends on bioavailability, diet, level of Se in the soil and drinking water. Selenium is supplied to the body with food in an organic form (selenomethionine, selenocysteine) and inorganic (selenine). Selenomethionine is provided in animal and vegetable diet, its bioavailability is up to $90 \%$ [23-25]. Selenomethionine covers half of the daily requirement for Se. Selenocysteine is also characterized by $90 \%$ bioavailability and is present in plant food [23-25]. Selenium in inorganic form has lower bioavailability - 50\% [23-25]. Recommended daily dose in diet for selenium ranges from $40-70 \mu \mathrm{g} / \mathrm{day}$ [25]. In Poland, the average daily intake is $27.8 \mu \mathrm{g} /$ day, while in Japan - $82.7 \mu \mathrm{g} /$ day and USA - $95.9 \mu \mathrm{g} /$ day [26]. As mentioned in the Introduction, there are reports suggesting that suboptimum Se levels may adversely affect human health, including lens metabolism [10, 22, 23].

Role of selenium and glutathione peroxidase in pathogenesis of ARC. As mentioned before, glutathione peroxidase is the key enzyme for protecting the lens against oxidative stress and ARC development. Selenium (Se) presence in a form of selenocysteine in a GPX molecule additionally enhances its enzymatic activity by almost 1,000-fold, compared to cysteine homologues [12]. A number of studies support the hypothesis that a lower serum selenium level is associated with decreased GPX activity in various tissues: blood [36, 37], kidneys [37], and liver, up to 99\% [38]. Furthermore, the study in rats by Cai indicates that decreased serum Se level decreases GPX activity in the lens, thus increasing the prevalence of cataracts [21]. The results of the current study also suggest that the increased prevalence of ARC (nuclear and cortical, Tabs. 4 -5) may be secondary to the decreased serum selenium levels.

The fact that GPX knockout $[18,22,39,40]$ or its GPX inhibition $[13,21]$ is associated with increased prevalence of cataract seems confirmation of the GPX role in ARC pathogenesis. According to Reddy, GPX-1 knockout resulted in damage to the cellular membranes of lens fibres and progressive nuclear opacity. However, no damage to lens epithelium or cortex has been shown, which can be explained by higher levels of glutathione in these structures, which has an established antioxidant effect $[41,42]$. Another study showed an increased epithelial resistance to the cytotoxic effect of $\mathrm{H}_{2} \mathrm{O}_{2}$ in transgenic animals with increased GPX activity, compared to non-transgenic animals [43]. It should be noted, however, that cells composing the lens nucleus or cortex do not have their own organelles. They therefore depend on their environment and adjacent lens epithelium which shows normal enzymatic activity. Considering the distance from the epithelium, the lens nucleus may be more susceptible to oxidative stress than the lens cortex. This corresponds to the current findings, that decreased serum Se levels correlated with the prevalence of nuclear cataract increased 4-fold, compared to the prevalence of cortical cataract (nuclear ARC vs. cortical ARC: OR 12.8 vs. 3.3).

The current study is the first to assess polymorphisms of glutathione peroxidase gene 1 (rs1050450) and 4 (rs713041) in ophthalmology. As shown above, statistical analysis did not confirm an association between LOCS III and SNP GPX-1 or GPX-4 (Tabs. 6 - 9). Mao (2016) did not show an association between Se and SNP GPX-1 or GPX-4 [44], which is in line with Donadio (2016), although the latter study only assessed SNP GPX-1 [32]. Obviously, the absence of correlations between ARC and assessed SNPs does not imply that there is no potential effect of other SNP GPX-1 or GPX-4 on glutathione peroxidase enzymes.

Association between selenium levels and prevalence of ARC. A number of correlational animal and clinical studies have been carried out to-date to determine the association between selenium levels and prevalence of ARC [21, 29, $45,46]$. In the opinion of the authors of the current study, they all have significant methodology-related limitations, which preclude reliable interpretation of results. The current study is the first to use LOCS III for cataract classification, which enabled statistical analysis of different ARC subtypes. Furthermore, the current study assumed the strictest sample selection criteria, which helped minimize the effect of artifacts seen in other studies.

The results of this study confirm a significant $(\mathrm{p}<.01)$ correlation between low selenium levels and ARC prevalence. In subjects with the lowest Se levels (1st quartile: Se 31.64$67.73 \mu \mathrm{g} / \mathrm{L}$ ), the prevalence of nuclear cataract was increased 12-fold, of cortical cataract - 3-fold, and of any ARC - 8-fold, compared to the reference group. These findings are in line with results reported by other authors $[21,29]$. In the study by Dawczyński [29], the study sample consisted of patients with mature cataract undergoing extracapsular cataract extraction (ECCE) only. This sample might have not been representative of the general population, especially if LOCS III was not applied. Furthermore, Se levels were determined 
in the study by using atomic absorption spectrometry (AAS), the accuracy of which is inferior to ICPMS. In a study carried out in the Finnish population in 1997, Knekt did not confirm the association between serum Se levels and ARC prevalence [45]. However, unlike the current study, the one by Knekt had a number of significant limitations: patients treated with diuretics were not excluded, LOCS III grading was not assessed, and Se levels were determined using atomic absorption spectrometry (AAS). The study group consisted of patients undergoing surgery due to mature cataract. The controls were volunteers who did not report cataract. However, their lens opacity was not assessed and they did not undergo an eye exam. Furthermore, fasting blood samples were not ensured and patients with diabetes were not excluded. Therefore, Se levels might have been masked by metabolic changes, medications, diabetic diet, as well as occult or manifest nephropathy. All the above could have decreased the reliability of Se assays and further statistical analyses. On the other hand, the study by Jacques found an association between Se levels of $>100 \mu \mathrm{g} / \mathrm{L}$ and increased prevalence of ARC. However, the results were on the verge of significance with $p>.05$ and $<.1$ [46]. Finally, methodology limitations of that study were the same as in Knekt's research [46]. The presented findings do not support the hypothesis that higher Se levels increase the prevalence of ARC (Tabs. 3 -6). Subjects in the 4 th quartile (i.e. with the highest serum Se levels) had increased OR for $\mathrm{n}$ uclear $(\mathrm{OR}=1,745$; Tab. 4) and cortical cataract $(\mathrm{OR}=1.036$; Tab. 5), although the findings were not significant $(p>.05)$. The OR in patients with posterior subcapsular cataract and highest Se levels was.91 (Tab. 6); however, the result was not significant. Jacques' findings have also not been confirmed in research performed in the Chinese population [47]. The Chinese study was carried out in a population inhabiting an industrial area with high pollution and high soil and water concentration of selenium. The authors reported no association between higher selenium concentrations and ARC prevalence. The prevalence of nuclear (23.7\%), cortical (22.4\%), and posterior sub-capsular (5.2\%) opacity in the study sample was comparable to the general Chinese population. These results, however, cannot be compared with those of the presented study, as the study by Li was based on LOCS II classification, and different criteria of clinical significance were applied to cataracts: $\geq \mathrm{N} 1, \geq \mathrm{C} 1, \geq \mathrm{P} 1$ [47].

Posterior sub-capsular cataract, which differs clinically and histologically from cortical or nuclear opacities, requires a separate comment. It can be induced by steroids and trauma, or develop secondarily to diabetes. However, there are cases of posterior sub-capsular cataract without an obvious cause. Histologically, there is no crystalline aggregation in posterior sub-capsular cataract, which is commonly seen in cortical and nuclear cataract. Vision impairment observed in patients with posterior sub-capsular cataract is primarily due to light scattered by the epithelial cell organelles which have migrated to the posterior pole of the lens. Epithelial cells show the highest enzymatic activity and the highest concentration of antioxidants, i.e. glutathione, among all lens structures. Therefore, oxidative stress seems to play a relatively minor role in posterior sub-capsular cataract. The above is consistent with the current findings, as is the lack of correlation between blood selenium levels and sub-capsular opacity grading as per LOCS III (Tab. 6).

\section{CONCLUSIONS}

Due to the confirmed association between serum selenium levels and age-related cataract, low serum selenium levels may constitute a potential risk factor for age-related cataract.

\section{Acknowledgment}

The authors gratefully acknowledge the contribution of Magdalena Ździebło and Ewa Putresza for data collection, and Karolina Kalisz translating the manuscript. The research was funded by the National Science Centre, Kraków, Poland (Grant No. DEC-2013/11/N/NZ5/03752).

\section{REFERENCES}

1. Collective work. Prevention of Blindness and Visual Impairment, World Health Organization website www.who.int/blindness/causes/priority/ en/index1.html. Accessed 30th June 2017

2. Schein OD, Cassard SD, Tielsch JM, Gower EW. Cataract surgery among Medicare beneficiaries. Ophthalmic Epidemiol. 2012; 19: 257-64

3. Collective work. Lens and Cataract. San Fransisco, American Academy of Ophthalmology, 2015; 65.

4. Truscott RJ, Friedrich MG. The etiology of human age-related cataract. Proteins don't last forever. Biochem Biophys Acta. 2016; 1860: 192-8.

5. Shiels A, Hejtmancik JF. Molecular Genetics of Cataract. Prog Mol Biol Transl Sci. 2015; 134: 203-18.

6. Petrash JM. Aging and age-related diseases of the ocular lens and vitreous body. Invest Ophthalmol Vis Sci. 2013; 54: 54-9.

7. Akpek EK, Smith RA. Current treatment strategies for age-related ocular conditions. Am J Manag Care. 2013; 19: 76-84.

8. Beebe DC, Holekamp NM, Shui YB. Oxidative damage and the prevention of age-related cataracts. Ophthalmic Res. 2010; 44: 155-65.

9. Michael R, Bron AJ. The ageing lens and cataract: a model of normal and pathological ageing. Philos Trans R Soc Lond B Biol Sci. 2011; 1568: $1278-92$.

10. Ganea E, Harding JJ. Glutathione-related enzymes and the eye. Curr Eye Res. 2006; 31: 1-11.

11. Truscott RJ. Age-related nuclear cataract-oxidation is the key. Exp Eye Res. 2005; 80: 709-25.

12. Arnér ES. Selenoproteins - What unique properties can arise with selenocysteine in place of cysteine? Exp Cell Res. 2010; 316: 1296-303.

13. Kisić B, Mirić D, Žorić L, Ilić A, Dragojević I. Reduced glutathione level and GSH-dependent enzyme activities in corticonuclear blocks of lenses in patients with senile cataract. Srp Arh Celok Lek. 2012; 140: 563-70.

14. Miric DJ, Kisic BB, Zoric LD, Mitic RV, Miric BM, Dragojevic IM. Xanthine oxidase and lens oxidative stress markers in diabetic and senile cataract patients. J Diabetes Complications. 2013; 27: 171-6.

15. Harding JJ. Free and protein bound glutathione in normal and cataractous human lens. Biochem. J. 1970; 117: 957-60.

16. Rathbun WB, Bovis MG, Holleschau AM. Glutathione peroxidase, glutathione reductase and glutathione-S-transferase activities in the rhesus monkey lens as a function of age. Curr Eye Res. 1986; 5: 195-9.

17. Rathbun WB, Bovis MG. Activity of glutathione peroxidase and glutathione reductase in the human lens related to age. Curr Eye Res. 2001; 5: 381-5.

18. Reddy VN, Giblin FJ, Lin LR, et al. Glutathione peroxidase-1 deficiency leads to increased nuclear light scattering, membrane damage, and cataract formation in gene-knockout mice. Invest Ophthalmol Vis Sci. 2001; 42: 3247-55.

19. Karaküçük S, Ertugrul Mirza G, Faruk Ekinciler O, Saraymen R, Karaküçük I, Ustdal M. Selenium concentrations in serum, lens and aqueous humour of patients with senile cataract. Acta Ophthalmol Scand. 1995; 73: 329-32.

20. Xing KY, Lou MF. Effect of $\mathrm{H}_{2} \mathrm{O}_{2}$ on human lens epithelial cells and the possible mechanism for oxidative damage repair by thioltransferase. Exp Eye Res. 2002; 74: 113-22.

21. Cai QY, Chen XS, Zhu LZ, et al. Biochemical and morphological changes in the lenses of selenium and/or vitamin $\mathrm{E}$ deficient rats. Biomed Environ Sci. 1994; 7: 109-115.

22. Flohé L Selenium, selenoproteins and vision. Dev Ophthalmol. 2005; 38: 89-102. 
23. Duffield AJ, Thomson CD, Hill KE, Williams S. An estimation of selenium requirements for New Zealanders. Am J Clin Nutr. 1999; 70: 896-903.

24. Thomson CD, Robinson MF, Butler JA, Whanger PD. Long term supplementation with selenate and selenomethionine:selenium and glutathione peroxidase in blood components of New Zealand women. Br J Nutr. 1993; 69: 577-588.

25. Combs GF Jr. Selenium in global food systems. Br J Nutr. 2001; 85: $517-47$.

26. Markiewicz-Żukowska Renata Selen w żywności http://www.gbcpolska. pl/sympozja/pdfy/slesin2010_borawska_markiewicz_zukowska2.pdf (access: 03/04/2018)

27. Thomson CD. Assessment of requirements for selenium and adequacy of selenium status: a review. Eur J Clin Nutr. 2004; 58: 391-402.

28. Lener M, Jaworska K, Muszyńska M, et al. Selenium as marker for cancer risk and prevention. Pol Przegl Chir. 2012; 84: 470-475.

29. Dawczynski J, Winnefeld K, Königsdörffer E, Augsten R, Blum M, Strobel J. Selenium and cataract-risk factor or useful dietary supplement? Klin Monbl Augenheilkd. 2006; 223: 675-80.

30. Jablonska E, Gromadzinska J, Reszka E, et al. Association between GPx1 Pro198Leu polymorphism, GPx1 activity and plasma selenium concentration in humans. Eur J Nutr. 2009; 48: 383-6.

31. Takata Y, King IB, Lampe JW, et al. Genetic variation in GPX1 is associated with GPX1 activity in a comprehensive analysis of genetic variations in selenoenzyme genes and their activity and oxidative stress in humans. J Nutr. 2012; 142: 419-26.

32. Donadio JL, Guerra-Shinohara EM, Rogero MM, Cozzolino SM. Influence of Gender and SNPs in GPX1 Gene on Biomarkers of Selenium Status in Healthy Brazilians. Nutrients. 2016; 8: 5 doi: 10.3390/ nu8050081.

33. Nirmalan PK, Robin AL, Katz J, et al. Risk factors for age related cataract in a rural population of southern India: the Aravind Comprehensive Eye Study. Br J Ophthalmol. 2004; 88: 989-94

34. Oishi N, Morikubo S, Takamura Y, et al. Correlation between adult diabetic cataracts and red blood cell aldose reductase levels. Invest Ophthalmol Vis Sci. 2006; 47: 2061-4.

35. Raman R, Pal SS, Adams JS, Rani PK, Vaitheeswaran K, Sharma T. Prevalence and risk factors for cataract in diabetes: Sankara Nethralaya
Diabetic Retinopathy Epidemiology and Molecular Genetics Study, report no. 17. Invest Ophthalmol Vis Sci. 2010; 51: 6253-61.

36. Hill KE, Burk RF, Lene JM. Effect of selenium depletion and repletion on plasma glutathione and glutathione dependent enzymes in the rat. J Nutr. 1987; 117: 99-104.

37. Nakane T, Asayama K, Kodera K, Hayashibe H, Uchida N, Nakazawa S. Effect of selenium deficiency on cellular and extracellular glutathione peroxidases: immunochemical detection and mRNA analysis in rat kidney and serum. Free Radic Biol Med. 1998; 25: 504-11.

38. Li X, Qu ZC, May JM. GSH is required to recycle ascorbic acid in cultured liver cell lines. Antioxid Redox Signal. 2001; 3: 1089 -1097.

39. Chan AW, Ho YS, Chung SK, Chung SS. Synergistic effect of osmotic and oxidative stress in slow-developing cataract formation. Exp Eye Res. 2008; 87: 454-61.

40. Wang H, Gao J, Sun X, et al. The effects of GPX-1 knockout on membrane transport and intracellular homeostasis in the lens. J Membr Biol. 2009; 227: 25-37.

41. Cheng W, Fu YX, Porres JM, Ross DA, Lei XG. Selenium-dependent cellular glutathione peroxidase protects mice against a pro-oxidantinduced oxidation of NADPH, NADH, lipids, and protein. FASEB J. 1999; 13: 1467-75.

42. Giblin FJ, Reddy VN. Pyridine nucleotides in ocular tissues as determined by the cycling assay. Exp Eye Res. 1980; 31: 601-9.

43. Reddy VN, Lin LR, Ho YS, et al. Peroxide-induced damage in lenses of transgenic mice with deficient and elevated levels of glutathione peroxidase. Ophthalmologica. 1997; 211: 192-200.

44. Mao J, Vanderlelie JJ, Perkins AV, Redman CW, Ahmadi KR, Rayman MP. Genetic polymorphisms that affect selenium status and response to selenium supplementation in United Kingdom pregnant women. Am J Clin Nutr. 2016; 103: 100-6.

45. Knekt P, Heliovaara M, Rissanen A, Aromaa A, Aaran R. Serum antioxidant vitamins and risk of cataract. BMJ. 1992; 305: 1392-4.

46. Jacques PF, Hartz SC, Chylack LT Jr, McGandy RB, Sadowski JA. Nutritional status in persons with and without senile cataract: blood vitamin and mineral levels. Am J Clin Nutr. 1988; 48: 152-8.

47. Li T, He T, Tan X, et al. Prevalence of age-related cataract in high selenium areas of China. Biol Trace Elem Res. 2009; 128: 1-7. 